Bond University

Research Repository

\title{
Not all systematic reviews can be completed in 2 weeks - but many can be (and should be)
}

Clark, Justin; Scott, Anna Mae; Glasziou, Paul

Published in:

Journal of Clinical Epidemiology

DOI:

10.1016/j.jclinepi.2020.06.035

\section{Licence:}

CC BY-NC-ND

Link to output in Bond University research repository.

Recommended citation(APA):

Clark, J., Scott, A. M., \& Glasziou, P. (2020). Not all systematic reviews can be completed in 2 weeks - but many can be (and should be). Journal of Clinical Epidemiology, 126, 163. https://doi.org/10.1016/j.jclinepi.2020.06.035

\footnotetext{
General rights

Copyright and moral rights for the publications made accessible in the public portal are retained by the authors and/or other copyright owners and it is a condition of accessing publications that users recognise and abide by the legal requirements associated with these rights.
}

For more information, or if you believe that this document breaches copyright, please contact the Bond University research repository coordinator. 
Title Page Information: reply to Yan et al.

Title

Not all systematic reviews can be completed in 2 weeks - but many can be (and should be).

Author names and affiliations

Justin Clark ${ }^{1}$, Anna Mae Scott ${ }^{1}$, Paul Glasziou $^{1}$

Institute for Evidence-Based Healthcare, Bond University, 14 University Dr, Robina QLD 4226.

Corresponding author

Justin Clark: phone: +61 07 55955455; email: jclark@bond.edu.au; postal address: Room 4_42,

Building 5, Bond University, 14 University Dr, Robina QLD, Australia, 4226. 


\section{Not all systematic reviews can be completed in 2 weeks - but many can be (and should be).}

Dear Editors,

We would like to thank Yan and colleagues for providing us with an opportunity to expand on the applicability of our 2 week Systematic Review (2weekSR) processes (1).

Yan and colleagues correctly point out that "it is important to recognise not all SRs are created equal and complexity of the [systematic review] topic can greatly impact the time spent on the review." We state on page 89 of the manuscript that our initial 2weekSR had a narrow PICO question and may not be representative of other SRs. We also note that the narrowness was deliberate - this is because the first 2 weekSR was intended to be a 'proof of concept.'

Yan and colleagues also note that "the authors did not mention nor include the time needed to familiarise researchers with these [SR automation] tools. This may possibly be due to the authors [sic] prior experience using such tools." As we state in Table 5 (Facilitators and barriers to completing a 2 weekSR), experience with the tools was one of the key facilitators of the 2 weekSR: "Pre-existing knowledge and ability to use the automation tools (e.g. SRAHelper, Word Frequency Analyser, etc.) eliminated the 'learning curve' and time."

Yan and colleagues' point, regarding the need for supplementing simulated decisions (made by the automation tools) with manual independent validation, does not apply to most of the tools we used. However, as the Journal's readers know, the output of RobotReviewer is only partial ( 4 of the 7 risk of bias domains) and ipso facto requires a manual check, whilst the RobotSearch tool has been extensively validated (2).

We appreciate Yan and colleagues' kind commendation of our 2 weekSR academic exercise. We are happy to share that the 2 weekSR process has so far been adopted on 5 SRs, which included a variety of SR types (intervention, prevalence, adverse events) and study designs (RCTs, observational studies, both). These SRs involved screening of 638 to 5471 references in title-abstract, 16 to 214 references in full-text, and included from 7 to 37 studies. They have involved teams of 4 to 6 , with four of the SR teams involving at least 1 team member with only some systematic review experience, and 1 team also involving a colleague with no prior SR experience. The duration of the 2 weekSRs ranged from 9 to 13 days, i.e. from less than 2 weeks to 2.5 weeks. Further 2 weekSRs are already in progress or currently in planning stages.

As the 2 weekSR methodology is particularly suited to the need for quick but robust and evidencebased decision-making, three of the above-mentioned 2 weekSRs were on COVID-related topics and were provided as input to decision-makers.

The 2 weekSR process is undergoing continual refinement and development, and we are planning to offer workshops to train interested colleagues in the approach.

Sincerely,

Justin Clark, Anna Mae Scott, Paul Glasziou

References 
1. Clark J, Glasziou P, Del Mar C, Bannach-Brown A, Stehlik P, Scott AM. A full systematic review was completed in 2 weeks using automation tools: a case study. Journal of clinical epidemiology. 2020;121:81-90.

2. Marshall IJ, Noel-Storr A, Kuiper J, Thomas J, Wallace BC. Machine learning for identifying Randomized Controlled Trials: An evaluation and practitioner's guide. Research synthesis methods. 2018;9(4):602-14. 